\title{
INEQUALITIES ON TIME SCALES: A SURVEY
}

\author{
R. Agarwal, M. Bohner and A. Peterson
}

Abstract. The study of dynamic equations on time scales, which goes back to its founder Stefan Hilger (1988), is an area of mathematics which is currently receiving considerable attention. Although the basic aim of this is to unify the study of differential and difference equations, it also extends these classical cases to cases "in between". In this paper we present time scales versions of the inequalities: Hölder, Cauchy-Schwarz, Minkowski, Jensen, Gronwall, Bernoulli, Bihari, Opial, Wirtinger, and Lyapunov.

Mathematics subject classification (2000): 34A40, 39A13.

Key words and phrases: Time scales, Dynamic equations, Measure chains.

\section{REFERENCES}

[1] R. Agarwal, M. Bohner, D. O’Regan and A. Peterson, Dynamic equations on time scales: A survey, 2000. Submitted.

[2] R. P. Agarwal AND M. Bohner, Quadratic functionals for second order matrix equations on time scales, Nonlinear Anal., 33:675-692, 1998.

[3] R. P. Agarwal AND M. Bohner, Basic calculus on time scales and some of its applications, Results Math., 35(1-2):3-22, 1999.

[4] R. P. Agarwal And P. Y. H. PANG, Opial Inequalities with Applications in Differential and Difference Equations, Kluwer Academic Publishers, Dordrecht, 1995.

[5] B. AUlBaCh AND S. HilgER, Linear dynamic processes with inhomogeneous time scale, In Nonlinear Dynamics and Quantum Dynamical Systems (Gaussig, 1990), volume 59 of Math. Res., pages 9-20, Akademie Verlag, Berlin, 1990.

[6] M. Bohner, S. Clark AND J. Ridenhour, Lyapunov inequalities on time scales, J. Inequal. Appl., 2000. To appear.

[7] M. Bohner AND B. KAYMAKÇALAN, Opial inequalities on time scales and some of its applications, 2000. Submitted.

[8] M. Bohner AND D. A. LuTZ, Asymptotic behavior of dynamic equations on time scales, J. Differ. Equations Appl., 7(1): 21-50, 2001

[9] M. Bohner And A. Peterson, First and second order linear dynamic equations on measure chains, $J$. Differ. Equations Appl., 2000. To appear.

[10] S. CHEN, Lyapunov inequalities for differential and difference equations, Fasc. Math, 23:25-41, 1991.

[11] G. Folland, Real Analysis: Modern Techniques and Their Applications, John Wiley and Sons, Inc., New York, second edition, 1999.

[12] G. H. Hardy, J. E. LittlewOOd and G. Pólya, Inequalities, Cambridge University Press, Cambridge, 1959.

[13] S. HiLger, Analysis on measure chains - a unified approach to continuous and discrete calculus, Results Math., 18:18-56, 1990.

[14] S. Hilger, Special functions, Laplace and Fourier transform on measure chains, Dynam. Systems Appl., 8(3-4):471-488, 1999. Special Issue on "Discrete and Continuous Hamiltonian Systems", edited by R. P. Agarwal and M. Bohner.

[15] R. HiLSCHER, A time scales version of Wirtinger's inequality with applications, 2000. Submitted.

[16] S. A. ÖZGÜN, A. ZAFER AND B. KAYMAKÇALAN, Gronwall-Bihari type inequalities on time scales, In Conference Proceedings of the Second International Conference on Difference Equations (Veszprém, 1995), pages 481-490, Amsterdam, 1997. Gordon and Breach. 